\title{
CHAVE ANALÍTICA PARA DETERMINAÇÃO DE DEZ VARIEDADES DE CANA-DE-AÇÚCAR (Saccharum spp.)
}

\author{
M.DE ALMEIDA ${ }^{1}$; L.A.ROCHELLE ${ }^{1}$; O.J.CROCOMO' \\ 'Departamento de Botânica-ESALQ/USP, C.P. 9, CEP: 13418-900-Piracicaba,SP \\ ${ }^{2}$ Centro de Biotecnologia Agrícola-ESALQ/USP, C.P. 9. CEP: 13418-900-Piracicaba,SP
}

\begin{abstract}
RESUMO: Utilizando dados obtidos sobre a atividade de isoenzimas de esterase e peroxidase, o teor de proteína total solúvel e o nível de sólidos solúveis (sacarose, grau Brix, bem como parâmetros organográficos de colno e follus já publicados), foi possível elaborar uma chave analítica para determinação de 10 variedades de canat-de-açúcar (Saccharum spp.): NA 56-79. IAC 52-150, IAC 64-257, SP 70-1143. SP 71-3146. SP 71-3149. SP 71-141)6. SP 716163, SP 71-6168 e SP 71-799.

Descritores: quimiotaxonomia, cana-de-açúcar, organografia, colmo, folha, isoenzimas, esterase, perovidase
\end{abstract}

\section{ANALYTICAL KEY FOR THE DETERMINATION OF TEN VARIETIES OF SUGARCANE (Saccharum spp.)}

ABSTRACT: Using the data on organographic and biochemical parameter (isoenzymes, total soluble protein and Brix values) characterization, it was possible to establish an analytical key to taxonomicaly classify the following sugarcane (Saccharum spp.) varieties: NA 56-79, IAC 52-150, IAC 64-257, SP 70-1143. SP 71-3146, SP 71-3149. SP 71-1406, SP 71-6163, SP 71-6168 and SP 71-799.

Key Words: chemotaxonomy, sugarcane, organographic characteristics, stalk. leaf, isoenzymes, esterase. peroxidase

\section{INTRODUÇÃO}

BACCHI (1983), caracterizou a cana-deaçúcar como pertencente ao gênero Saccharum L., da sub tribo Saccharae, Tribo Andropogone, Família Graminea, Ordem Glumiflorae, Classe Monocotyledoneae, Sub Divisão Angiospermae e Divisão Embryophyta siphonogama.

Segundo JESWIET (1925), o gênero Saccharum L., apresenta as seguintes espécies: $S$. officinarum L., S. spontaneum L., S. sinensis Roxb. e $S$. barberi Jew.. No entanto, ARTSCHWAGER \& BRANDES (1958), incluem para o mesmo gênero mais duas espécies: $S$. robustum Jew, e $S$. edule Hask.. De todas as espécies citadas são consideradas puras apenas $S$. spontaneum L. e $S$. robustum Jesw., sendo as demais de origem híbrida (STEVENSON, 1965).

Ainda segundo STEVENSON (1965), as variedades atuais de cana-de-açúcar são originadas de espécics e híbridos do gênero Saccharum L.. Por centenas de anos grarde parte do açúcar era extraído de variedades da espécie $S$. officinarum L., mas outras espécies do mesmo gênero têm sido usadas na produção comercial do açúcar na Índia e na China, por isso nunca foi correto referir-se a cana-de-açúcar categoricamente como sendo a espécies $S$. officinarum L. e hoje certamente é incorreto (STEVENSON, 1965).

BACCHI (1983), observou que atualmente, devido a grande incidência do mosaico nesta espécie, as variedades até então utilizadas, passaram a ser substituídas por híbridos das espécics que apresentavam maior resistência à doença.

Com a crescente procura de novos híbridos mais resistentes c produtivos. apareceram centenas de novas varicdades, causando uma enorme dificuldade na identificação das mesmas, que nem scmpre, com os métodos tradicionais de observações morfológicas, podiam ser reconhecidas taxonomicamente.

LARSEN (1969), estabeleceu que "todas as manifestações morfológicas inerentes de diferenças varietais devem ultimamente, ter diferença bioquímica, mas nem todas essas diferenças são refletidas morfologicamente. Assim, as diferenças bioquímicas deverão ser mais numerosas do que as morfológicas". 
Uma demonstração deste postulado foi relatada por ALMGARD \& LANDERGREN (1974), quando o Swedish Official Committes of Cultivares impediu a introdução de uma variedade agronomicamente melhorada, denominada 'Timo'. 'Timo' era o resultado do cruzamento de 'hero' $x$ 'Parvus' e poderia ser diferenciado morfologicamente de 'Hero' mas não de 'Parvus'. No entanto, através de isoenzimas de esterase demonstrou-se que 'Hero' e 'Timo' apresentavam duas bandas delgadas, enquanto que 'Parvus' apresentava somente uma. Assim a variedade 'Timo' teve sua aprovação, pois confirmou-se pela técnica isoenzimática que de fato elas poderiam ser consideradas variedades diferentes.

THURMAN et al. (1967) estudando as mobilidades eletroforéticas das desidrogenases glutâmicas de sementes de diferentes espécies de Fabaceae, concluiram que o método apresentava possibilidades de sucesso quanto à classificação sistemática.

A técnica de isoenzima começa a ser aplicada extensivamente em variedades, mas espera-se que seja um importante método suplementar para a identificação dos mesmos. A identificação dos clones por zimogramas tem sido possível em batatas (DESBOROUGH \& SHARON, 1968; DESBOROUGH, 1969); abacaxi (BREWBAKER, 1966). As cultivares são comumente identificadas isoenzimaticamente.

A aplicação de isoenzimas e outras técnicas químicas em taxonomia de plantas é de desenvolvimento relativamente recente. ALSTON \& TURNER (1963) consideram a enzimologia comparada e possivelmente a química comparativa como sendo o último nível de quimiotaxonomia.

O uso de múltiplas formas moleculares de enzimas, ou isoenzimas fornecem um possível caminho de se obter marcadores bioquímicos que facilitam a interpretação e o reconhecimento de híbridos intervarietais ou interespecificos (LEWONTIN, 1974; LEWIS, 1980).

O presente trabalho é fundamentado em experimentos sobre organografia das folhas $e$ colmos (ALMEIDA \& CROCOMO, 1994a; 1994b), bem como da análise da atividade de isoenzimas de esterase e peroxidase, nível de proteína total solúvel e teor de sólidos solúveis (ALMEIDA \& CROCOMO, 1994c), de dez variedades de cana-de-açúcar. Dos resultados obtidos foi possível a elaboração de uma chave analítica das dez variedades estudadas, com base nos dados obtidos anteriormente.

\section{MATERIAIS E MÉTODOS}

As dez variedades de cana-de-açúcar estudadas são: NA 56-79, IAC 52-150, IAC 64-257, SP 70-1143, SP 71-799, SP 71-1406, SP 71-3146, SP 71-3149, SP 71-6163 e SP 71-6180, que foram plantados em maio de 1982 em uma mesma área da Estação Experimental da Copersucar em Piracicaba (SP), sob condições as mais uniformes possíveis (climáticas, edáficas e culturais), afastando desta maneira, possíveis variações determinadas pelo meio. Para maior uniformização durante a coleta das amostras em maio de 1984, estipulou-se que as mesmas só seriam observadas quando afastadas um mínimo de três metros de bordadura, quando então a exposição à luz $e$ ao vento tornam-se uniformes.

A descrição botânica das variedades de cana-de-açúcar poderia ser feita tomando-se plantas de várias regiões do Estado de São Paulo, onde elas são cultivadas. Entretanto, seriam condições idênticas de solo, clima e tratos culturais, fatores estes que poderiam influenciar, em parte, as características morfológicas e bioquímicas das plantas que foram observadas.

Análise organográfica: Os estudos organográficos do colmo e da folha das variedades de cana-de-açúcar estão apresentados em ALMEIDA \& CROCOMO, 1994c; ALMEIDA \& CROCOMO, 1994a).

Análises bioquímicas: A caracterizaçãobioquímica foi feita através da detecção de isoenzimas das enzimas esterase e peroxidase, onde extratos das gemas corrrespondentes aos entre-nós de número 5 a 10 , foram submetidos a separação eletroforética, seguindo o método de DAVIS (1964), bem como da determinação do nível de sólidos solúveis (sacarose) pelo processo refratométrico, expressos em ${ }^{\circ}$ Brix, com um refratômero manual modelo $A O$ T/C e do teor de proteína total solúvel. A metodologia está descrita em ALMEIDA \& CRÓCOMO, 1994c.

\section{RESULTADOS}

Com base nos resultados obtidos nos estudos organográficos no colmo e folha (ALMEIDA \& CROCOMO, 1994c e ALMEIDA \& CROCOMO, 1994a) e na caracterização bioquímica (ALMEIDA \& CROCOMO, 1994c) foi elaborada a chave analítica para a determinação de dez variedades de cana-de-açúcar apresentada a seguir: 


\section{Chave para determinação das variedades}

1. Largura da região mediana do limbo foliar superior a $5 \mathrm{~cm}$.

1' Largura da região mediana do limbo foliar inferior a $5 \mathrm{~cm}$.

2. Diâmetro do entre-nó mediano menor que $2,6 \mathrm{~cm}$; ausência dos pêlos 22 e 4 nas gemas 5 ou 10; ponta das folhas dobradas e formato da lígula do tipo crescente a orbicular crescente

'SP 70-1143'

2'. Diâmetro do entre-nó mediano maior que $2,6 \mathrm{~cm}$; presença dos pêlos 22 e 4 nas gemas 5 ou 10; ponta das folhas retas e formato da lígula do tipo cintiforme-crescente ou crescente com losango.

3. Ausência dos pêlos 5 nas gemas 5 ou 10; formato da lígula do tipo crescente com losango e abundante quantidade de cera no colmo

'SP71-1406'

3'. Presença dos pêlos 5 nas gemas 5 ou 10 ; formato da lígula do tipo cintiforme-crescente e regular quantidade de cera no colmo... 4

4. Comprimento da bainha menor que $28,0 \mathrm{~cm}$; sólidos solúveis (sacarose) maior que 24 graus Brix e abundante quantidade de joçal na bainha 'SP71-6163'

4'. Comprimento da bainha menor que $28,0 \mathrm{~cm}$; sólidos solúveis (sacarose) menor que 24 graus Brix e joçal praticamente ausente na bainha

'SP 71-3146'

5. Formato do "dewlap" do tipo deltóide crescente alto e curto ou ligulado médio-alto ascendente e abundante ou praticamente sem cera no colmo

5'. Formato do "dewlap" do tipo quadrado médio alto ascendente ou quadrado crescente alto $\mathrm{e}$ curto e média quantidade de cera no colmo

6

6. Formato do "dewlap"do tipo ligulado médioalto ascendente; bainha com abundante quantidade de joçal, formato da lígula do tipo deltóide a deltóide-crescente e ponta das folhas curvas ....................... 'SP 71-3149'

6'. Formato do "dewlap" do tipo deltóide crescente alto e curto; bainha praticamente sem joçal; formato da lígula do tipo cintiforme-crescente e ponta das folhas dobradas.
7. Presença dos pêlos $3,4,16$ e 31 nas gemas 5 ou 10; abundante quantidade de cera no colmo, comprimento médio do colmo maior que $3,0 \mathrm{~m}$; sólidos solúveis (sacarose) maior que 24 graus Brix e proteína total solúvel a $\mathrm{pH} 5,5$ igual a $9,94 \mathrm{mg} / 100 \mathrm{mg}$ de matéria seca e a $\mathrm{pH} 8,0$ igual a $47,65 \mathrm{mg} / 100 \mathrm{mg}$ de matéria seca

'NA 56-79'

7'. Ausência dos pêlos 3, 4, 16 e 31 nas gemas 5 ou 10; pouca cera no colmo; comprimento médio do colmo menor que $3,0 \mathrm{~m}$; sólidos solúveis (sacarose) menor que 24 graus Brix e proteína total solúvel a $\mathrm{pH} 5,5$ igual a 6,47 $\mathrm{mg} / 100 \mathrm{mg}$ de matéria seca e a $\mathrm{pH} 8,0$ igual a $34,50 \mathrm{mg} / 100 \mathrm{mg}$ de matéria seca

'IAC 64-257'

8. Formato do "dewlap" do tipo quadrado subcrescente alto e curto; ponta das folhas curvas e ausência dos pêlos 22 nas gemas 5 ou 10

'SP 71-6180'

8'. Formato do "dewlap" do tipo quadrado médio alto ascendente; ponta das folhas retas ou dobradas e presença dos pêlos 22 nas gemas 5 ou 10 .

9. Formato da lígula do tipo cintiforme-crescente; praticamente sem joçal nas bainhas; depressão da gema ausente ou rara em todo o colmo; ponta das folhas retas; comprimento médio do colmo maior que $2,5 \mathrm{~m}$; comprimento dos entrenós medianos maior que $16,0 \mathrm{~cm}$; e diâmetro menor que $2,7 \mathrm{~cm}$; com presença de pêlos $2 \mathrm{a}$, $3,4,10,16,26,31$ a e 32 nas gemas 5 ou 10

IAC 52-150'

9'. Formato da lígula do tipo crescente com losango; presença abundante de joçal na bainha; depressão da gema presente em todo colmo; ponta das folhas dobradas; comprimento médio do colmo menor que $2,5 \mathrm{~m}$; comprimento dos entre-nós medianos menor que $16,0 \mathrm{~cm}$ e diâmetro maior que $2,7 \mathrm{~cm}$; e ausência dos pêlos $2 a, 3,4,10,16,26,31 a$ e 32 nas gemas 5 ou 10 .

'SP 71-799'

\section{CONCLUSÕES}

Dos estudos feitos para a caracterização das 10 variedades de cana-de-açúcar analisados: NA 56-79, IAC 52-150, IAC 64-257, SP 70-1143, SP 71-3146, SP 71-3149, SP 71-1406, SP 71-6163, SP 71-6180 e SP 71-799 destacam-se as seguintes conclusões: 
1. As características organográficas mais evidentes na caracterização das variedades são: largura da região mediana do limbo foliar; comprimento e presença de joçal na bainha; formato do "dewlap", lígula e aurícula; presença de pêlos na gema e formato de gema;

2. Apenas o comprimento do limbo foliar não é suficiente para identificá-los;

3. A região mediana do colmo é a mais recomendada para estudos de caracterização, tanto do ponto de vista morfológico, como bioquímico;

4. Os sólidos solúveis (sacarose) em graus Brix e a proteina total solúvel, mesmo sendo pouco viáveis, têm um valor satisfatório na determinação das variedades;

5. As isoenzimas de peroxidase permitem agrupar as variedades assim: 'IAC 52-150' com 'SP 71799' e 'SP 71-3146' com 'SP 71-3149' e 'SP 716163';

6. O padrão eletroforético das isoenzimas de esterase $\epsilon$ específico para cada uma das 10 variedades estudadas;

7. As isoenzimas de peroxidase e esterase apresentam-se constantes em uma mesma variedade;

8. Com os dados morfológicos e bioquímicos obtidos foi possível a elaboração de uma chave analítica para a determinação das variedades.

\section{REFERÊNCIAS BIBLIOGRÁFICAS}

ALMEIDA, M.; CROCOMO, O.J. Organografia de dez cultivares de cana-de-açúcar (Saccharum spp.). I. Colmo. Revista de Agricultura, Piracicaba, v.69, n.1, p.41-65, 1994a.

ALMEIDA, M.; CROCOMO, O.J. Organografia de dez cultivares de cana-de-ą̧úcar (Saccharum spp). II. Folha. Revista de Agricultura, Piracicaba, v.69, n.2, p.161-182, 1994b.

ALMEIDA, M.; CROCOMO, O.J. Caracterização organoganográfica e bioquímica de dez cultivares de cana-de-açúcar (Saccharum spp.). Scientia Agricola, Piracicaba, v.51, n.3, p.422-429, 1994c.

ALMGARD, G.; LANDEGREN, U. Isoenzimatic variation used for the identification of barley cultivars. Zeitschrift fuer Pflazenzuchtung, Berlin, v.72, n.1, p.63-73, 1974.
ALSTON, R.E.; TURNER, B.L. Biochemical systematics. Englwood Cliffs: Prentice-Hall, 1963. $115 \mathrm{p}$.

ARTSCHWAGER, E.; BRANDES, E.W. Sugarcane (Saccharum officinarum L.). Washington: USDA, 1958. 307p. (Agriculture Handbook, 122).

BACCHI, O.O.S. Botânica da cana-de-açúcar. In: ORLANDO FILHO J., Coord. Nutrição e adubação da cana-de-açúcar no Brasil. Piracicaba: IAA/ PLANALSUCAR, 1983. p.25-37. (Coleção PLANALSUCAR, 2).

BREWBAKER, J.L. Enzyme fingerprints for the plant detective. Hawaiian Botanical Society Newsletter, v.5, n.1, p.1-3, 1966.

DAVIS, B.J. Disc electrophoresis. II. Method and application to human serum proteins. Annual New York Academy Science, New York, n.121, p.407427, 1964.

DESBOROUGH, S.; SHARON, J.M. Potato variety identification by use eletroforetic patterns of tuber proteins and enzymes. Journal of Experimental Botany, Oxford, v.18, p.100-109, 1968.

DESBOROUGH, $S$. Tuber proteins from haploide, self and cultivars of group tuberosum separated by acid gel disc eletroforesis. Theoretical \& Applied Genetics, Berlin, v.39, p.43-47, 1969.

JESWIET, J. Beschrijving der soorten van het swikerriet. Elf de bijdrage. Bijdrage tot de systematick van het geslacht Saccharum. Meded Proefst. Java - Suikerind: p.391-404, 1925.

LARSEN, A.L. Isoenzymes and varietal identification. Seed World, Des Plainer, v.104, n.8 p.5-6, 1969.

LEWIS, W.A. Polyploid: biological relevance. New York: Plenum Press, 1980. 583p.

LEWONTIN, R.C. The genetic basis of evolutionary change, New York: Columbia University Press, 1974. 325p.

STEVENSON, G.C. Genetics and breeding of sugar cane. London: Longmans, 1965. 284p.

THURMAN, D.A.; BOULTER, D.; DERBYSHIRE, E.; TURNER, B.L. Eletrophoretic mobilities of formic and glutamic dehydrogenase in the Fabaceae: a systematic survey. New Phytologist, Cambridge, v.66, p.37-48, 1967.

Entregue para publicação em 20.04.94

Aceito para publicação em 10.09.94 